\title{
On the Acquisition of the Prenominal Adjective Order by Kuwaiti EFL Learners
}

\author{
Maye A. Alotaibi \\ PAAET \& CBS, Kuwait \\ Abdullah M. Alotaibi (Corresponding author) \\ PAAET \& CBE, Kuwait \\ E-mail: alotaibi917@gmail.com
}

Doi:10.7575/aiac.alls.v.8n.1p.1

URL: http://dx.doi.org/10.7575/aiac.alls.v.8n.1p.1
Received: 06/09/2016

Accepted: 14/12/2016

\begin{abstract}
This study aims to test the extent to which 80 Kuwaiti EFL learners are aware of prenominal adjective ordering system in English, particularly how it affects Kuwaiti EFL learners' grasp on English grammar. In addition, it checks whether the English proficiency level of the participants plays a role in their answers on the test. Therefore, a prenominal adjective ordering test was used to measure the participants' ability to produce the correct order of prenominal adjectives in English. This research instrument was chosen on the basis of the researchers' belief that this type of test leads to uncovering the causes beyond the correct/wrong answers provided by the participants on the test. Following data analysis, the results reveal that Kuwaiti EFL learners may not be fully aware of the prenominal adjective ordering system in English (total mean=48.75\%). The t-test shows that the English proficiency level of the participants plays a crucial role in the production of prenominal adjectives in English. In particular, there is a statistically significant difference between the answers of the advanced (65\%) and intermediate learners $(32.5 \%)$. The number of correct answers provided by the advanced learners is higher than that provided by the intermediate learners. Regarding the types of error made by the participants, it has been argued that the most noticeable ones are due to first language (L1) negative transfer. Finally, the study concludes with some pedagogical implications and recommendations for further research.
\end{abstract}

Keywords: Prenominal adjective ordering system, Second Language Acquisition (SLA), Error Analysis (EA), L1 transfer, Kuwaiti EFL learners.

\section{Introduction}

Adjective placement has been the subject of many studies in the past three decades since their ordering system could be quite complex and unpredictable, varying form one language to another. Adjectives vary widely cross-linguistically on the basis of their position before or after the noun they modify. Adjectives placed before the nouns they modify are called prenominal adjectives, while those placed after the modified noun are called postnominal ones. Some languages allow their adjectives to be placed before and after the modified noun. For example, prenominal adjectives are normally used in English with few exceptions such as nothing particular, nothing important and something different, in which the adjectives are used postnominally. Regarding adjective ordering, the order of multiple adjectives within the adjective phrase differs from one language to another. For instance, in English, a specific adjective ordering system is applied to arrange the adjectives in a restricted order which differs from other languages. Such restricted order may be considered a stumbling block for L2 learners. Thus, this study aims to examine the awareness of 80 Kuwaiti EFL learners of prenominal adjective ordering in English. To this end, the researchers opted for a prenominal adjective ordering test in order to investigate whether Kuwaiti EFL learners are able to produce prenominal adjectives in English in a correct order. Since few studies have investigated the acquisition of this phenomenon, this study aims to bridge this gap. Also, the study checks whether the English proficiency level of the participants plays a role in the production of prenominal adjectives in the correct order. Ultimately, the study investigates the possible causes of correct/wrong answers which the participants may provide on the test.

\section{Background and literature review}

\subsection{Theoretical background}

When it comes to ordering adjectives, the literature suggests that native speakers of various languages around the world have particular preferences in ordering words and phrases, implying that certain words usually precede others (Richards, 1977). For instance, it has been noted by Boucher \& Osgood (1969) that there is a universal preference to convey the good news first, then report the bad news. As a result, the sequence: a powerful dangerous medication is much more preferred than the sequence a dangerous powerful medication because the denotation of powerful is positive, whereas the denotation of dangerous is negative. This tendency is referred to as the "Polyanna Hypothesis". 
In the same vein, based on a number of psycholinguistic studies that focus of sequencing phenomena (e.g. Bock, 1982; Lapata et al., 1999), it has been argued that frequency has a major role to play in the ordering of entities, which also includes the sequencing of adjectives. Such that, adjectives which occur more frequently than other adjectives are expected to come first due to their higher level of activation in the mental lexicon. This higher level of activation motivates the production of frequently used adjectives as opposed to less frequent ones. These claims are deduced in line with the general principles pertinent to the effect of frequency on sequencing phenomena. Additionally, taking into account the common correlation between the length of the word and its frequency, it is expected that words which are short in length precede those which are long since they are likely to be produced faster.

In case of prenominal adjectives, it has been hypothesised that in a sequence of prenominal adjectives, the ones which are more nouny are ordered in a way so that they can be closer to the head noun they modify (Bever, 1970). For instance, note that in prenominal adjectives in English, the ones related to size e.g. small, big, etc. usually preceded the ones related to colour e.g. yellow, black, etc. On the basis of this argument, one may suggest that adjectives of colour are more nouny compared to adjectives of size (Bever, ibid). This leads to the following section in which we discuss prenominal adjective sequence in English

\subsection{Prenominal adjective sequence in English}

Research on the sequence of prenominal adjectives in English has revealed that even though many researchers would be unanimous on the existence of a certain sequence of such adjectives, the jury is still out on their categorization methods. For instance, regarding the sequence of words in noun phrases in English, it has been surmised that nouns phrases usually have six sections, namely, determiner (Det), subjective or evaluative adjective, measurement adjective, coloration adjective, material adjective, and finally the head noun (Baily, 1975, cited in Celce-Murcia \& LarsenFreeman, 1999, p. 393). This ordering can be seen in Table 1 below:

Table 1. Order of words in noun phrases in English (Baily, 1975)

\begin{tabular}{llllll}
\hline Section 1 & Section 2 & Section 3 & Section 4 & Section 5 & Section 6 \\
\hline the & ugly & big & blue & cotton & shirt \\
\hline these & awful & tiny & black & polyester & pants \\
\hline
\end{tabular}

However, on the basis of Baily's categorisation of noun phrases order, Svatko (1979) has created narrower categories and expanded on Baily's work (cited in Celce-Murcia \& Larsen-Freeman, 1999, p. 394). This classification is illustrated in Table 2 below:

Table 2. Svatko's (1979) categorisation of noun phrases order on the basis of Baily (1975)

\begin{tabular}{lllllllll}
\hline Det & Opinion & Size & Shape & Condition & Age & Colour & origin & Head N \\
\hline A & $\begin{array}{l}\text { well- } \\
\text { made }\end{array}$ & large & elongated & good & antique & purple & American & boat \\
& & & & & & & & \\
\hline
\end{tabular}

The previous discussion shows that the categorization methods followed to classify the order of words in a particular phrase are still blurred. For example, concerning prenominal adjectives order in English, Scott (2002, cited in Svenonius, 2008, p. 35) has gone into great lengths to describe their placement: "ordinal, cardinal, subject comment, evidential, size, length, height, speed, depth, width, temperature, wetness, age, shape, colour, nationality/origin, material". One may observe that the sequence of prenominal adjectives in English is quite extensive and confusing. Hence, it can be argued that such order may be problematic to acquire for EFL/ESL learners. The next section sheds light on adjective order in Arabic in order to examine whether such order may influence Arab EFL learners' acquisition of adjective order in English. In other words, does L1 negative transfer affect the acquisition of prenominal adjectives order in English?

\subsection{Adjective order in Arabic}

Adjectives in Arabic usually appear postnominally, where they agree with the head noun they modify in definiteness, number, person, gender, and case (Fassi-Fehri, 1999, p. 107). The sequence of adjectives is governed by hierarchical restrictions not only in Arabic, but in other languages as well. Examples from Arabic demonstrate some of these restrictions:
1) Pal-kitaab-u the-book-NOM 'the big red book'
2) qahwat-un lahmar-u the-red-NOM 1-kabiir-u coffee-Nom Brazilian-NOM black-NOM excellent-NOM 'An excellent black Brazilian coffee' 
3) Pamsah-

bi-1-mandiil-i

clean-I with-the-handkerchief-GEN
'I clean with the beautiful small handkerchief

$\underline{\text { s-sayiir-i }}$

1-jamiil-i

the-small-GEN the-beautiful-GEN

An examination of example (1) shows that in addition to agreeing with the head noun it modifies in number, person, gender, and Case, the adjective is marked with the definite article, whilst in example (2), the adjective is not marked with the definite article. In other words, it is indefinite. Additionally, example (3) shows that Case spreads to all adjectives in the construction. One may also notice that the order of adjectives in Arabic is somewhat similar to that of attributive adjectives in French or English, the difference is that adjectives are mainly prenominal in English, but postnominal in Arabic (see examples 1-3):

4) An ugly small (rectangular) green box

5) Une petite (rectangulaire) boîte verte laide

In fact, a number of researchers have argued that the relative sequencing of the different categories of adjectives could be the same cross-linguistically. This claim can be supported by several pieces of evidence. For instance, the hierarchical restriction on the sequence of nominal adjectives denoting object, which is suggested by Sproat \& Shih $(1988,1990)$, in addition to that on nominal adjectives denoting events, in Cinque (1994), follow the same sequence found in direct A-N languages e.g. Germanic and indirect A-N languages e.g. Romance. Interestingly, the same sequence can also be found in verb-final languages such as Thai. However, such a sequence is not completely similar, leading to problems for $\mathrm{L} 2$ learners. The next section reviews some studies on the acquisition of adjective order.

\subsection{Studies on the acquisition of prenominal adjectives order}

Through reviewing a number of studies on the acquisition of prenominal adjectives order, one may propose that the adjective sequence system in the English language implies that it essentially relies on a grammatical convention as opposed to an innate sense of order. In this context, Hare \& Otto $(1978$, p. 190) argue that the most preferred prenominal adjective sequence in English is described as follows: size, colour, material, and noun. Their argument is based on a small experiment. Particularly, if asked to arrange the words duck, yellow, rubber, and little in a sequence, most adult native speakers of English would say: a little yellow rubber duck even though they have not been taught to arrange them in such an order. Hypothesising that the adjective sequence in English is based on grammatical convention might lead to the conclusion that the speakers who have similar languages to English may have a similar approach to arranging adjectives when they learn English. Therefore, one may argue, at least theoretically, that native speakers of Chinese and Korean may generate similar patterns in ordering adjectives, whilst native speakers of Nepali and Indian who are learning English as a second or foreign language may generate different patterns to those found in English. In sum, the idea that learners of English as a second/foreign language have a tendency to transfer knowledge of their first language into English may imply that speakers of languages that are distinctly different from English may produce different mistakes compared to those whose languages are similar to English. This means that Arab EFL learners may produce different patterns of adjectives since English and Arabic are typologically quite different.

Based on the previous literature, it seems that several studies (e.g. Alotaibi 2014; Alotaibi and Alajmi 2015; Zibin and Altakhaineh 2016 among others) have been conducted to investigate the acquisition of various English phenomena by Arabic-speaking EFL learners. However, little attention has been given to the acquisition of prenominal adjective ordering by Arabic-speaking EFL learners, in general, and Kuwaiti in particular. Thus, this study aims to bridge this gap. Specifically, it aims to investigate the type of errors made by Kuwaiti EFL learners when they produce prenominal adjectives in English. In this study, we aim to show how potential answers to some of the most prominent questions in Second Language Acquisition (SLA) can be supplied. The following are the research questions:

1. To what extent are Kuwaiti EFL learners aware of prenominal adjective ordering in English?

2. What type of errors, if there, do they make when they produce prenominal adjectives and why?

3. Does the English proficiency level of the participants play a role in their performance on the test?

\section{Methodology}

\subsection{Sample}

The participants who took part in the study were 80 Kuwaiti EFL learners, doing their undergraduate degrees at the Public Authority of Applied Education and Training (PAAET). The participants' mean age was 23 years old. The 80 participants were divided into 46 males and 34 females. To validate the results, the participants, who were randomly chosen, are currently registered in this college. They were divided into two groups according to their scores on the English Placement Test (EPT): those who scored 50-69 on the EPT were considered Intermediate Learners (ILs), whilst those who scored $70-85$ were considered Advanced Learners (ALs). The 80 participants were divided equally into 40 ILs and 40 ALs. Due to the complexity and unpredictability of the prenominal adjective ordering system in English, the researchers chose intermediate and advanced learners to participate in the study. Also, many studies show that the proper order of prenominal adjectives is acquired late in L2 context. Specifically, it has been proposed by Sorace (2005) that the features or phenomena related to fields that are at the interface of syntax and other disciples such as semantics, phonology, etc. are more problematic to acquire in L2 acquisition compared to the phenomena that are purely syntactic. This may lead to a degree of variability even in the answers provided by learners with high proficiency levels. The participants of this study have studied English at schools in Kuwait for twelve years and have already done two main English courses at the CBE i.e. E 161 and E 261. These courses deal with many complex syntactic and semantic structures in English, such as relative clauses, conditionals and prenominal adjectives order. With regard to 
ethical consideration, the participants were informed that their participation in the test was voluntary; they were informed that they can leave anytime if they feel stressed or uncomfortable.

\subsection{Instrument}

\subsubsection{The test}

In order to measure the participants' ability to produce prenominal adjectives in English properly, a reordering prenominal adjective test was used as an elicitation instrument (see Appendix A). This test has been used by Hare \& Otto (1978) in their study. This test was not only used to measure the participants' ability to produce prenominal adjectives in a correct order, but also helps to discover the causes beyond the errors made by the participants on the test. In the current study, the test included eight sentences representing different types of adjectives as follows:

Table 3. Types and order of prenominal adjectives on the test

\begin{tabular}{ll}
\hline Sentence No. & Types and order of the adjectives on the test \\
\hline 1 & condition - age - colour - origin \\
\hline 2 & opinion - size - colour \\
\hline 3 & shape - age - origin \\
\hline 4 & opinion - shape - colour \\
\hline 5 & opinion - size - colour \\
\hline 7 & size - age - origin \\
\hline 8 & opinion - age - origin \\
\hline
\end{tabular}

Table 3 shows that every type of prenominal adjectives, based on Svatko's (1979) classification, is represented at least once.

\subsubsection{Error Analysis (EA)}

In general, an Error Analysis (EA) approach can bring to light some insight into the sequence of prenominal adjectives in L2 acquisition. For instance, it has been proposed that errors related to L2 acquisition need to be investigated in accordance with an EA approach. This is due to the fact that such approach: (1) pays special attention to the types of errors made by L2 learners; and (2) endeavours to provide a systematic explanation for them (Mitchell and Myles, 2004). Additionally, through an in-depth analysis of the types of error made by L2 learners, it has been observed that one of the main reasons for these errors is the interference of the first language (L1) (Mitchell and Myles, ibid). Hence, Saville-Troike (2006, p. 38-39) explains that under EA, errors can be categorized into two types, namely, interlingual and intralingual. The former refers to the errors made under the influence of $\mathrm{L} 1$, whereas the latter refers to those errors made as a result of lack of knowledge of the target language. Intralingual errors are usually classified as developmental errors since they develop when L2 learners overgeneralise L2 rules on the basis of their limited knowledge of the target language. In a nutshell, EA can be a useful approach used to obtain potentially accurate results and explanations for the errors made by L2 learners when they attempt to order prenominal adjectives in English.

\subsubsection{Statistical analysis}

In order to see whether Kuwaiti EFL learners are aware of the correct order of prenominal adjectives, the Statistical Package for Social Sciences (SPSS) analysis was used. This analysis includes the calculation of percentages, means and standard deviations of the participants' answers on the test. These calculations were conducted to confirm or refute the hypotheses above. For instance, a t-test was conducted to check whether the difference between the results of ALs and ILs is statistically significant or not. Also, the percentages of the most problematic prenominal adjective order patterns have been calculated to show the possible causes behind these errors.

\section{Results and discussion}

The main goal of this study was to measure the ability of Kuwaiti EFL learners to produce correct prenominal adjective order in English, and to account for the errors if found. In order to test whether the participants' English proficiency level affected their answers, a t-test was used. Table 4 below shows the results.

Table 4. Results of t-test of differences between (ALs) and (ILs)

\begin{tabular}{lllllll}
\hline Proficiency Level & $\mathrm{N}$ & $\mathrm{M}$ & $\mathrm{SD}$ & $\mathrm{t}$ & $\mathrm{df}$ & Sig. \\
\hline Advanced Learners (ALs) & 40 & 6.5 & 1.75 & 0.87 & 78 & $0.014^{* *}$ \\
\hline Intermediate Learners (ILs) & 40 & 3.25 & 1.25 & & & \\
\hline
\end{tabular}

**Significance level $<0.05$ 
Examining Table 1, it is clear that the difference between the answers of ALs and ILs is lower than (0.05), which means that the difference between the two groups was statistically significant. ALs $(\mathrm{m}=6.5)$ performed better than ILs $(m=3.25)$ on the test. The means show that ALs obtained a higher number of correct answers as opposed to ILs; hence, there is a prominent statistical significance between the two groups on the tests. The percentage of correct answers obtained by ALs demonstrates that the English proficiency level of the participants contributed to their correct answers on the test as shown in Table 5.

Table 5. Percentage of correct answers by ALs and ILs on the test

\begin{tabular}{ll}
\hline Proficiency level & Percentage of correct answers \\
\hline Advanced Learners (ALs) & $65 \%$ \\
\hline Intermediate Learners (ILs) & $32.5 \%$ \\
\hline Total mean & $48.75 \%$ \\
\hline
\end{tabular}

Table 5 shows that the overall percentage of correct answers by both ALs and ILs (48.75\%) may indicate that Kuwaiti EFL learners may not be fully aware of the order of prenominal adjectives in English. Several mistakes were made by the tested groups on the test, showing that they probably have a vague idea about the sequencing rules of prenominal adjectives in English. The number and percentage of correct answers provided by both groups with regard to the eight sentences used on the test are illustrated in Table 6.

Table 6. Number and percentage of correct answers by ALs and ILs in terms of prenominal adjective types

\begin{tabular}{llll}
\hline Types and orders of the adjectives on the test & \multicolumn{2}{l}{ Participants } & $\begin{array}{l}\text { Percentage of correct } \\
\text { answers }\end{array}$ \\
\cline { 2 - 3 } & ALs & ILs & $35 \%$ \\
\hline condition - age - colour - origin & $50 \%$ & $20 \%$ & $47.5 \%$ \\
\hline opinion - size - colour & $65 \%$ & $30 \%$ & $54 \%$ \\
\hline shape - age - origin & $70 \%$ & $37.5 \%$ & $49 \%$ \\
\hline opinion - shape - colour & $62.5 \%$ & $35 \%$ & $47.5 \%$ \\
\hline opinion - size - colour & $65 \%$ & $30 \%$ & $52.5 \%$ \\
\hline size - age - origin & $70 \%$ & $35 \%$ & $56 \%$ \\
\hline opinion - age - origin & 72.5 & $40 \%$ & $49 \%$ \\
\hline shape - condition -colour & $65 \%$ & $32.5 \%$ & $48.75 \%$ \\
\hline Overall percentage of correct answers & $65 \%$ & $32.5 \%$ & \\
\hline
\end{tabular}

Table 6 demonstrates that the participants have not encountered problems with certain items on the test, since their results on each item are roughly the same. However, it seems that the participants achieved less on the first item i.e. condition - age - colour - origin, since it has four adjectives in comparison with other items. In other words, there is possibly no evidence that the types of adjective play a role in the acquisition of prenominal adjectives order in English. However, the number of adjectives may affect their production by EFL learners. This means that the more adjectives the participants have to arrange, the more likely they will get the order wrong.

Finally, the reasons why the participants have little awareness of prenominal adjectives order may be attributed to L1 negative transfer. Kuwaiti Arabic (KA), which may behave the same as Modern Standard Arabic (MSA) in terms of adjective order, has normally postnominal adjectives. The only case where prenominal adjectives appear in Arabic is in the Adjectival Synthetic Genitives (SGAs). Such structure is formed by an adjective followed by a noun (Fehri 1999, p. 106). The prenominal adjective in SGAs will not be discussed here any further, since it is normally one single adjective followed by one single noun; hence, there is no need for an adjective order. Below are some examples (1-5) from KA which may explain the reasons behind the errors made by the participants on the test:

1. jasim Sind-uh luSb-ah iiniyy-ah hilw-ah kbiir-ah Jasim has-hetoy-FSG Chinese-FSG beautiful-FSG big-FSG 'Jasim has a beautiful big Chinese toy.'

2. Pana sare:t sayyaar-ah yaabaaniyy-ah kbiir-ah I bought car-FSG Japanese-FSG big-FSG

'I bought a big Japanese car.'

3. sadeg-i Gind-uh luSb-ah mdaawara-ah hilw-ah 


ALLS 8(1):1-8, 2017 triend-my has-he beautiful-FSG

'My friend has a beautiful big toy.'

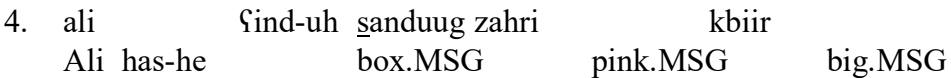

'Ali has a big pink box'

5. abdullah Gind-uh sayyaar-ah jdiid-ah hilw-ah

Abdullah has-he car-FSG new-FSG beautiful-FSG

'Abdullah has a beautiful new car.'

Apart from being in a postnominal position, the adjective order in examples (1-5) is different from that of English. The adjective order in example (1) is origin - size - opinion, in example (2) is origin - size, in example (3) is shape opinion, in example (4) colour - size and finally in example (5) is age - opinion. It is clear that there is a preference to start describing a noun using origin/nationality first. In Arabic, it is common to start with the origin of the item before any other type of adjectives. This was apparent in the participants' answers on the test as follows.

6. *I like that Japanese old green dented car that usually parks in front of my house.

7. *Walid gave me a German old round clock.

8. *I have bought some French slim big trousers.

9. *My father has a Spanish new wonderful clock.

Examples (6-9) demonstrate that speakers of KA seem to start describing the items with the origin adjective as they normally do in Arabic. Based on our experience as a non-native speaker of English, we used to move the noun to the end and the start ordering the English adjectives the same way we order them in Arabic. In other words, we just move the noun to the end as follows:

Table 7. The transfer of L1 rule into L2 in terms of the prenominal adjective order

\begin{tabular}{ll}
\hline The adjective order in Arabic & The outcome in English \\
\hline Noun + origin - size - opinion & origin - size - opinion + Noun \\
\hline
\end{tabular}

Another instance, apart from origin, which can be observed in example (9), *My father has a Spanish new wonderful clock, indicates that Kuwaiti speakers placed the age before opinion (see example 5 in the Arabic data, where age precedes opinion in Arabic). As a result, this could be the reason why Kuwaiti EFL learners provided a wrong answer in example (9); they transferred their L1 knowledge into L2.

All in all, Kuwaiti ALs performed better than ILs in terms of producing the prenominal adjectives in a correct order. The differences of the prenominal adjective ordering system between Arabic and English are possibly the main causes of the errors made on the test, resulting in little awareness of this phenomenon.

\section{Conclusion and recommendations}

The ultimate goal of this study was to check whether Kuwaiti EFL learners are aware of the prenominal adjective ordering system in English by measuring their ability to reorder these adjectives. The overall percentage of correct answers of both ALs and ILs (48.75\%) indicates that Kuwaiti EFL learners may not be fully aware of the complex nature of prenominal adjectives order in English. The results of the study also revealed that the English proficiency level of the participants played a role in their answers on the test. There was a statistically significant difference between the answers of ALs and ILs on the test. In particular, ALs performed better than ILs. The number of correct answers provided by ALs is higher than that provided by ILs. An analysis of the types of error made demonstrated that L1 negative transfer played a crucial role in the production of prenominal adjectives in a wrong order.

On the basis of these findings, it could be suggested that English teachers and curriculum designers need to acquaint EFL learners with the appropriate order of prenominal adjectives in English, showing them that languages crosslinguistically may differ in their ordering systems. The hieratical order suggested by Svatko's (1979) may be a good example to be followed. As a result, Arab EFL learners in general, and Kuwaiti EFL learners in particular, may produce more accurate sentences, especially since English has a rich system of prenominal adjectives. Raising EFL learners' awareness of this issue may improve their language production skills. Consequently, they may feel more confident when they speak. Lastly, further exploration of the acquisition of complex syntactic and semantic structures e.g. conditionals and dative alternation by EFL learners may be needed to shed light on the mechanisms by which such structures are acquired.

\footnotetext{
${ }^{1}$ This order is detected in example (1).
} 


\section{References}

Alotaibi, A. (2014). The comprehension of English lexical collocations by Kuwaiti EFL learners. International Journal of English Language and Linguistics Research, 2(3), 1-12.

Alotaibi, A, \& Alajmi, H. (2015). The acquisition of the passive alternation by Kuwaiti EFL learners. International Journal of English Linguistics, 5(1), 44-52. DOI: 10.5539/ijel.v5n1p44.

Bever, T. G. (1970). The cognitive basis for linguistic structures. In J. R. Hayes, editor, Cognition and the Development of Language. New York: Wiley.

Bock, J. K. (1982). Toward a cognitive psychology of syntax: Information processing contributions to sentence formation. Psychological Review, 89, 1-47. DOI:10.1037/0033-295X.89.1.1

Boucher, J., \& Osgood, C. E. (1969). The Polyanna Hypothesis. Journal of Verbal Learning and Verbal Behavior, 8, 18. DOI: $10.1016 / \mathrm{S} 0022-5371(69) 80002-2$

Celce-Murcia, M., \& Larsen-Freeman, D. (1999). The grammar book: An ESL/EFL teacher's course. Boston: Heinle \& Heinle Publishers.

Fehri, A. F. (1999). Arabic modifying adjectives and DP structures. Studia Linguistica, 53(2), 105-154.

Hare, V. C., \& Otto, W. (1978). Development of preferred adjective ordering in children, grades one through five. Journal of Educational Research, 71, 190-193.

Lapata, M., McDonald, S., \& Keller, F. (1999). Determinants of adjective-noun plausibility. Proceedings of the 9th Conference of the European Chapter of the Association for Computational Linguistics, 30-36.

Mitchell, R. and Myles, F. (2004). Second language learning theories (2nd Ed). London: Edward Arnold.

Richards, M. M. (1977). Ordering preferences for congruent and incongruent English adjectives in attributive and predicative contexts. Journal of Verbal Learning and Verbal Behavior, 16(4), 489-503. DOI: 10.1016/S00225371(77)80042-X

Saville-Troike, M. (2006). Introducing second language acquisition. Cambridge: Cambridge University Press.

Svenonius, P. (2008). The position of adjectives and other phrasal modifiers in the decomposition of the DP. In L. McNally, \& C. Kennedy (Eds.), Adjectives and adverbs: Syntax, semantics, and discourse (pp. 16-42). Oxford: Oxford University Press.

Zibin, A, \& Altakhaineh, A. R. M. (2016). Acquiring the English causative alternation: Evidence from the University of Jordan. International Journal of Applied Linguistics and English Literature, 5(3), 7-15. DOI:10.7575/aiac.ijalel.v.5n.3p.7.

\section{Appendix A}

1) Please, circle your English proficiency level based on the English Placement Test (EPT):
A) Advanced
B) Intermediate

2) Please, write the adjectives in the brackets in the correct order.

1. I like that car that usually parks in front of my house. (green, dented, Japanese, old)

2. My bother has a dog. (white, big, beautiful)

3. Walid gave me a ............................. clock. (German, round, old)

4. A …....................... box. (square, yellow, big)

5. A $\ldots \ldots \ldots \ldots \ldots \ldots \ldots \ldots \ldots \ldots \ldots$ ornament. (pink, wonderful, small)

6. I have bought some.......................... trousers. (big, French, slim)

7. My father has a ..............................clock. (Spanish, wonderful, new)

8. I have got a pair of $\ldots \ldots \ldots \ldots \ldots \ldots \ldots \ldots \ldots \ldots$ toys. (damaged, hearth-shaped, red)

\section{Appendix B}

Arabic sounds

\begin{tabular}{|c|c|c|}
\hline Arabic consonants/vowels & Symbols & Description \\
\hline 4 & $?$ & voiceless glottal stop \\
\hline ب ب & $\mathrm{b}$ & voiced bilabial stop \\
\hline 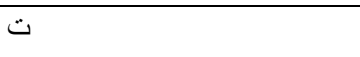 & $\mathrm{t}$ & voiceless dento-alveolar stop \\
\hline$\dot{H}$ & $\theta$ & voiceless inter-dental fricative \\
\hline ج & $\mathrm{j}$ & voiced post-alveolar affricate \\
\hline
\end{tabular}




\begin{tabular}{|c|c|c|}
\hline$\tau$ & $\underline{\mathrm{h}}$ & voiceless pharyngeal fricative \\
\hline$\dot{\tau}$ & $\mathrm{x}$ & voiceless uvular fricative \\
\hline د & $\mathrm{d}$ & voiced dento-alveolar stop \\
\hline$\dot{j}$ & ð & voiced alveolar fricative \\
\hline 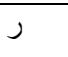 & $\mathrm{r}$ & voiced alveo-palatal trill \\
\hline j & $\mathrm{z}$ & voiced alveolar fricative \\
\hline 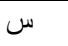 & $\mathrm{s}$ & voiceless alveolar fricative \\
\hline 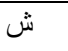 & $\int$ & voiceless alveo-palatal fricative \\
\hline 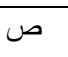 & $\underline{\mathrm{S}}$ & voiceless alveolar emphatic fricative \\
\hline ض & $\underline{\mathrm{d}}$ & voiced alveolar emphatic stop \\
\hline b & $\underline{\mathrm{t}}$ & voiceless dento-alveolar emphatic stop \\
\hline ظ & $\underline{\partial}$ & voiced alveolar emphatic fricative \\
\hline$\varepsilon$ & $\mathrm{q}$ & voiced pharyngeal fricative \\
\hline$\dot{\varepsilon}$ & $\gamma$ & voiced uvular fricative \\
\hline ف & $\mathrm{f}$ & voiceless labio-dental fricative \\
\hline ق & $\mathrm{q} / \mathrm{g}^{\mathrm{i}}$ & voiceless/voiced uvular stop \\
\hline ك & $\mathrm{k}$ & voiceless velar stop \\
\hline J & 1 & voiced alveolar lateral \\
\hline 5 & $\mathrm{~m}$ & voiced bilabial nasal \\
\hline ن & $\mathrm{n}$ & voiced alveolar nasal \\
\hline$\circ$ & $\mathrm{h}$ & voiceless glottal fricative \\
\hline 9 & $\mathrm{w}$ & voiced labio-velar glide \\
\hline ي & $\mathrm{y}$ & voiced palatal glide \\
\hline$\Gamma$ & $\mathrm{a}$ & low short central unrounded \\
\hline $1 /$ & $\mathrm{u}$ & high short back rounded \\
\hline 1.1 & i & high short front unrounded \\
\hline i & aa & low long central unrounded \\
\hline وو & $\mathrm{uu}$ & high long back rounded \\
\hline يبي & ii & high long front unrounded \\
\hline 9 & o: & mid long back rounded \\
\hline او & aw & low short front unrounded + labio-velar glide \\
\hline اي & ay & low short front unrounded + palatal glide \\
\hline يبي & ee & mid long front unrounded \\
\hline
\end{tabular}

\footnotetext{
${ }^{\mathrm{i}}$ These symbols represent the voiceless and voiced uvular stop.
} 